\title{
Spectroscopic features of cancer cells: FTIR spectroscopy as a tool for early diagnosis
}

Francisco Santos ${ }^{a, b}$, Sandra Magalhães ${ }^{a}$, Magda Carvalho Henriques ${ }^{b}$, Margarida Fardilha ${ }^{b}$ and Alexandra Nunes ${ }^{a}$

a iBiMED - Institute of Biomedicine, Department of Medical Sciences, University of Aveiro, Aveiro, Portugal

b Signal Transduction Laboratory, iBiMED - Institute of Biomedicine, Department of Medical Sciences, University of Aveiro, Aveiro, Portugal

Corresponding author: Alexandra Nunes

iBiMED - Institute of Biomedicine, Department of Medical Sciences

University of Aveiro

Agra do Crasto, 3810-193, Aveiro, Portugal

alexandranunes@ua.pt

\begin{abstract}
Globally, cancer is one of the leading causes of death, is one of the leading causes of death worldwide and so the development of strategies for an early diagnosis of cancer is of great importance. Since Biochemical alterations precede morphological changes in cells and tissues, so studying cancer metabolome seems like a reasonable approach for early diagnosis, prognosis and to follow treatment progression. Fourier-transform infrared (FTIR) spectroscopy is a valuable tool for studying the metabolome of biological samples, such as cancer cell lines. Unlike staining procedures and other histopathologic approaches, this technique is rapid, non-destructive and does not require reagents. The spectral differences that result from probing the biochemical composition of cancer and normal cells are indicative of distinct metabolic profiles, which allows for allow the discrimination of different cells. Using FTIR spectroscopy and multivariate statistical analysis, several alterations concerning the content of lipids, proteins, nucleic acids and carbohydrates have been identified in cancer cells, some of which can be regarded as potential biomarkers. This review focuses on FTIR spectroscopy as a metabolomics tool to study and characterize cancer cell lines.
\end{abstract}


Keywords: Cancer; metabolomics; metabolic profile; FTIR spectroscopy; cell lines; multivariate analysis

\section{Introduction}

Cancer is the second leading cause of death worldwide. It is estimated that every year there are 14 million new cases of the disease every year, causing almost 9 million deaths $(1,2)$. Despite the efforts in finding new diagnostic and therapeutic strategies, cancer patients exhibit relatively low survival rates. One of the reasons for that is the fact that the disease is often detected when it is well established, meaning that it is diagnosed at a late stage, only when morphological alterations are observed, in many cases resulting in a poor prognosis. that in many situations it is associated with a poor prognosis (3). Furthermore, costs associated with cancer treatment are a huge problem to for healthcare systems, so it is imperative to discover new strategies to diagnose cancer as early as possible. for the early diagnosis and treatment of cancer as early as possible $(4,5)$.

Similar to every other disease, cancer exhibits several cellular and molecular alterations (6-8). Because cancer cells display a very distinct and unique metabolic phenotype, cancer is basically considered a metabolic disease. Moreover, an altered metabolism has been recognized as one of the hallmarks of cancer $(9,10)$. Since it is the endpoint of cellular biological processes, metabolism carries an imprint of the cell's phenotype and, therefore, it is indicative of its activity. Common alterations present in several types of cancer cells include increased glucose uptake, increased rate of glycolysis, decreased mitochondrial activity, low bioenergetic status and abnormal phospholipid metabolism (11-13). In addition to these general metabolic alterations, specific metabolites have been implicated in particular types of cancer, such as 1stearoylglycerol, citrate and spermine in prostate cancer $(14,15)$ and glycine in breast cancer (16). In this way Thus, measuring the metabolites themselves appears to be a reasonable approach to study diseased cells (17).

The study of the metabolome provides rapid, sensitive and reproducible data and has been widely used to understand phenotypic and metabolic alterations associated with cancer cells (18-20). The main advantage of metabolomics lies on the 
fact that the metabolome can reflect early changes that occur in the cell, allowing the identification of diagnostic biomarkers before morphological changes occur $(18,21)$. Furthermore, metabolomics allows to monitor the efficacy of medical interventions and the understanding of molecular mechanisms involved in cancer and carcinogenesis $(21,22)$.

The main metabolomic techniques used for metabolic fingerprinting are nuclear magnetic resonance (NMR) spectroscopy, mass spectrometry and vibrational spectroscopy, which includes FTIR spectroscopy $(17,23)$. The latter has gained relevance in biomedical research because it provides an inexpensive, rapid, high-throughput and non-destructive analysis of a wide range of samples, including biological fluids, tissues and cells $(24,25)$. FTIR spectroscopy probes the chemical composition and molecular structure of the analyzed samples $(17,26)$. Moreover, since biochemical alterations lead to spectral differences, it is possible to discriminate samples with distinct metabolic profiles $(3,27)$. In this review, we intend to explore the importance of FTIR spectroscopy in cancer metabolomics and compile work that has been conducted in the study of cancer cell lines using FTIR spectroscopy.

\section{FTIR Spectroscopy}

FTIR spectroscopy is a form of vibrational spectroscopy. Therefore, it is based on the vibrations of the atoms in a molecule, caused by the interaction of infrared (IR) radiation with matter (28-30). However, not every molecule shows IR absorptions: only the vibrations that cause a change in the dipole moment of the molecule absorb IR radiation, and the larger this change, the more intense will be the absorption band will be (29). Molecular vibrations that are produced (mainly stretching and bending) are specific to the composition and structure of analyzed samples $(24,26,29)$. The IR region can be divided into three regions: near-IR $\left(13,000-4,000 \mathrm{~cm}^{-1}\right)$, mid-IR $\left(4,000-400 \mathrm{~cm}^{-}\right.$ $\left.{ }^{1}\right)$ and far-IR $\left(<400 \mathrm{~cm}^{-1}\right)$ (29). Nevertheless, many of the studies that have been conducted regarding FTIR spectroscopy and cell lines included only the mid-IR region because, aside from being very informative, most of the molecules absorb its radiation $(31,32)$. 
FTIR spectroscopy has shown potential as a tool for analyzing cells. Unlike histopathologic techniques, FTIR spectroscopy is rapid, non-invasive, cost-effective, easy to operate, reagent-free and requires minimal sample preparation. Furthermore, experimental materials can be re-used for further analysis and, as it is a method without technician interference, it tends to be less subjective $(17,25,30)$. Despite these great advantages, one of the main disadvantages of this technique is the strong absorption that water exhibits in the mid-IR region. As biological tissues and cells are mainly composed by water, this may constitute a problem in FTIR analysis of biological samples. Nevertheless, this drawback can be overcome simply by dehydrating the samples, ridding them of the water $(17,33-35)$.

Since IR spectra reflect the chemical composition of a given sample, alterations that occur in key macromolecules, such as proteins, lipids, carbohydrates and nucleic acids, can be monitored (36-39). Furthermore, IR spectrum can be considered a molecular fingerprint of the sample, meaning that changes that occur in biomolecules, for instance, during carcinogenesis, will modify this fingerprint, enabling the discrimination between cancer and normal cells $(37,40-42)$.

To analyze FTIR data, both direct spectra analysis and statistical tools can be used. In spite of its importance, Since the direct analysis of the IR spectra, although important, is difficult and subjective, so multivariate statistical tools analyses are widely used instead to study metabolomics data., such as IR spectra of biological samples $(43,44)$. One of the most commonly used tools is principal component analysis (PCA), which is an unsupervised model, so it does not require an initial knowledge about the samples $(43,45)$. PCA reduces thousands of variables characteristic of a spectrum to a few principal components and is used as an exploratory tool that groups samples according to shared similarities $(43,46)$. The results of a PCA can be presented in the form of score and loadings plots; score plots present the separation of groups observed in the samples; while loadings plots indicate variables that are responsible for the discrimination $(44,46)$. After the samples are analyzed with an unsupervised model, other statistical methods can be applied, such as partial least square - discriminant analysis (PLS-DA). This is a supervised model, meaning that an initial knowledge about the samples is required (e.g. cancer cells vs. normal cells) and can be used if the 
discrimination provided by PCA is insufficient $(43,44,47)$. After the use of appropriate multivariate analysis tools, it is possible to create quantitative and qualitative classification models that make analysis of spectroscopic data approach more objective and, in some cases, almost automatic.

\section{Cell lines for in vitro study of cancer}

Cells are composed by several macromolecules, such as proteins, lipids, nucleic acids and carbohydrates (24). Therefore, the study of cells can provide a great deal of information regarding metabolic processes and absence or presence of disease (48).

Human cancer-derived cell lines are considered an important asset in biomedical research among the other tools of studying cancer. Since they offer an almost unlimited source of cells, are relatively easy to work with, exhibit a high degree of homogeneity and provide consistent and reproducible results, cancer cell lines have become the most used experimental model to study cancer. Furthermore, the use of cancer cell lines evades ethical issues that are associated with the use of animal and human tissues $(49,50)$.

Cancer cell lines are widely used to study the biology of cancer and in the development and testing of anticancer drugs, and many of the results that are obtained with cell lines are extrapolated to human cancers in vivo (51-55). The most commonly used approaches for the study of cells rely on staining procedures, which can be expensive, time-consuming and potentially cause harmful effects on the cells (56). Therefore, new approaches to study cell lines, mainly such as FTIR spectroscopy, have emerged in the last years, showing promising results $(36,41,57)$.

\section{FTIR spectroscopy applied to cancer cell lines}

FTIR spectroscopy has proven to be a valuable tool in cancer metabolomics. When analyzing biological samples, such as cells, there are key spectral regions that need to be considered. The $3000-2800 \mathrm{~cm}^{-1}$ region is mainly associated to lipids. Proteins are mostly characterized by two bands in the $1800-1300 \mathrm{~cm}^{-1}$ region: amide I, between 1700 and $1600 \mathrm{~cm}^{-1}$, and amide II, which peaks at $1540 \mathrm{~cm}^{-1}$, which are sensitive to the secondary structure of proteins; however, the amide I band is the most frequently used for this type of analysis. Also, in the $1800-1300 \mathrm{~cm}^{-1}$ region, the 
shoulder band at $\sim 1740 \mathrm{~cm}^{-1}$ is assigned to phospholipids, and the bands between 1480 and $1300 \mathrm{~cm}^{-1}$ have been attributed to amino acid side chains and fatty acids. Lastly, the major bands in the $1300-900 \mathrm{~cm}^{-1}$ region arise mainly due to carbohydrates (particularly glycogen) and phosphates associated with nucleic acids $(17,58)$. Furthermore, any changes in intensity or shape of bands or shifts to lower or higher frequencies, may indicate cellular alterations (58). A more detailed description of the mid-IR bands and their assignments can be consulted in table 1 .

\section{a. Spectral characteristics of cancer cell lines}

A typical IR spectrum of cancer cells is presented in figure 1. The spectrum represents an average of 8 spectra, which were acquired in a Fourier-transform infrared spectrometer (Alpha Platinum ATR, Bruker), controlled by OPUS software ( ${ }^{\circledR}$ Bruker). The spectra were obtained over the wavenumber range $4000-600 \mathrm{~cm}^{-1}$, with a resolution of $8 \mathrm{~cm}^{-1}$ and 64 co-added scans. The cell suspension was air-dried to remove water and, therefore, prevent its strong absorption. The spectral assignments for the cells were made according to table 1.

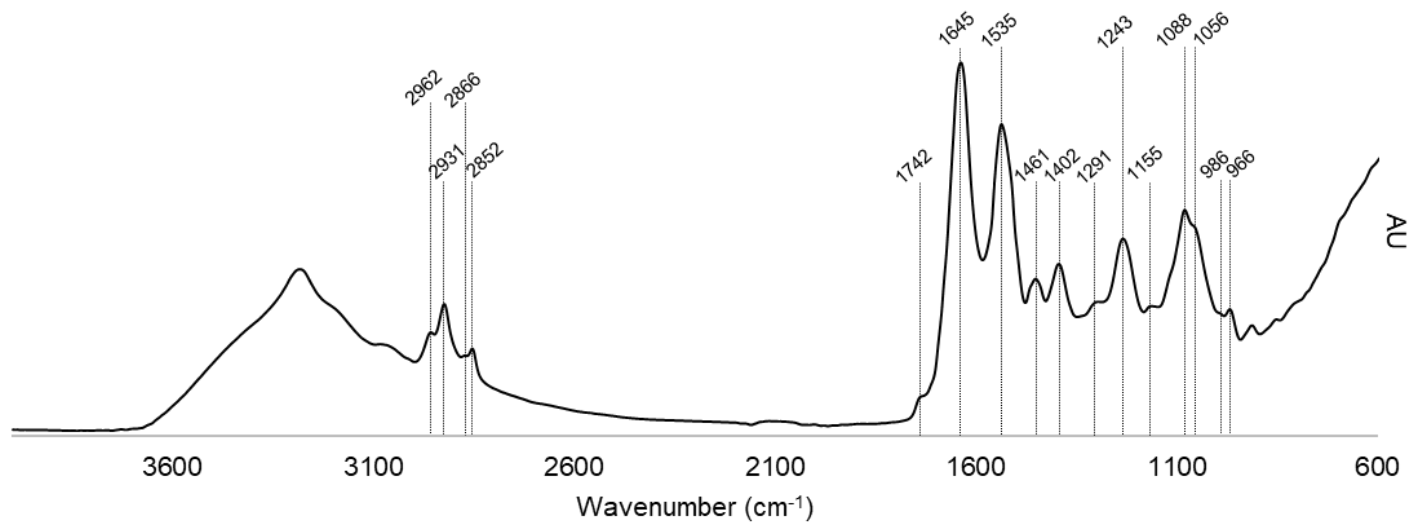

Figure 1: IR spectrum of prostate cancer cells LNCaP in the $4000-600 \mathrm{~cm}^{-1}$ region with the main spectroscopic signals. The spectrum represents the average of 8 spectra. X-axis: wavenumber $\left(\mathrm{cm}^{-1}\right)$; Yaxis: arbitrary units (AU).

The study of cancer cell lines with FTIR spectroscopy came to light when Rigas and colleagues observed that several colon adenocarcinoma cell lines (LoVo, SW1116, HCT-15, SW403, SW480) had similar spectra to those of colon cancer tissues (59). In a subsequent study, Rigas and Wong compared the same cell lines and an additional adenocarcinoma lineage (SKCO1) to normal and malignant colon tissues. They observed 
that these cells shared many characteristics with malignant colon tissues, such as an increased hydrogen-bonding of the phosphodiester groups of nucleic acids (57). In addition, they observed that the symmetrical $\mathrm{PO}_{2}{ }^{-}$stretching causes a band shift from $1082 \mathrm{~cm}^{-1}$ (in normal tissue) to $1086 \mathrm{~cm}^{-1}$ (in adenocarcinoma cells). In the $1010-950$ $\mathrm{cm}^{-1}$ region, two bands were discovered in adenocarcinoma cell lines: one at $972 \mathrm{~cm}^{-1}$, assigned to nucleic acids and symmetrical stretching mode of dianionic phosphate monoesters of phosphorylated proteins, and the other at $991 \mathrm{~cm}^{-1}$, which varies amongst cell lines and wasn't assigned to any particular biochemical component (57). Previous results obtained with HCT-15 cells also indicated that the phosphodiester stretching bands are related to nucleic acids (60). Lastly, Rigas and Wond studied the amide I band in the $1700-1600 \mathrm{~cm}^{-1}$ region, assigned to the in-plane $\mathrm{C}=\mathrm{O}$ stretching vibration weakly coupled with $\mathrm{C}-\mathrm{N}$ stretching and in-plane $\mathrm{N}-\mathrm{H}$ bending of the amide groups of proteins. They observed an increase in the relative amount of $\beta$-sheets, in relation to $\alpha$-helical segments, in adenocarcinoma cells and malignant tissue in comparison with normal tissue (57). It is already known that $\beta$-sheets are highly present in less soluble proteins that are likely to form aggregates $(61,62)$. Similar to neurodegenerative diseases, protein aggregation has been found to be present in many types of tumors and cancer cell lines, mainly involving aggregates of the tumor suppressor p53 (63-65), which can play an important role in carcinogenesis and drug resistance (66).

In a study comparing the uterine cervical adenocarcinoma cell line SiSo with cervical adenocarcinoma tissue and exfoliated malignant and normal cervical cells, Neviliappan and colleagues observed that several spectral bands of the malignant tissue and exfoliated cells and the SiSo cell line were noticeably different from those of the normal exfoliated cells (67). The bands at 1047 and $1025 \mathrm{~cm}^{-1}$ (usually called glycogen bands) are associated mostly with $\mathrm{C}-\mathrm{O}$ stretching and bending of the $\mathrm{C}-\mathrm{OH}$ groups of carbohydrates and were significantly reduced in the malignant tissue and exfoliated cells, and in the SiSo cell line (67). Similarly, the band at $1155 \mathrm{~cm}^{-1}$, assigned to the $\mathrm{C}-\mathrm{OH}$ stretching mode of carbohydrates, exhibited a lower peak in the abnormal cases due to the decrease of the glycogen levels. A shift in the frequency from $1080 \mathrm{~cm}^{-1}$ (in normal cases) to $1085 \mathrm{~cm}^{-1}$ (in abnormal cases) was also observed, indicating a strong 
intermolecular interaction that occurs in nucleic acids, suggesting that DNA packing is tighter and higher in malignant tissue and exfoliated cells and in the SiSo cell line. Also, an increase of intensity of the band at $970 \mathrm{~cm}^{-1}$ was observed in the abnormal cases. Furthermore, a peak at $1170 \mathrm{~cm}^{-1}$ was detected in malignant tissue, exfoliated cells and SiSo cell line, which is derived from the $\mathrm{C}-\mathrm{OH}$ groups of tyrosine, serine and threonine of cell proteins, indicating an increase in the phosphorylation of the $\mathrm{C}-\mathrm{OH}$ groups (67). It has been shown that an increase of the phosphorylation of these three amino acids by oncoproteins is an important event that occurs during carcinogenesis (68). Another shift observed in the spectra of the malignant tissue, exfoliated cells and the SiSo cell line occurred in the band at $1400 \mathrm{~cm}^{-1}$ : there was an increase of the intensity of this band in these samples, which might be related to structural changes in the methylene chains of lipids (67).

Later, in 2004, Fujioka and colleagues applied FTIR spectroscopy to compare three gastric cancer cell lines (AGS, SNU-1 and NCI-N87) with normal gastric mucosal epithelial cells (69). In this study, they analyzed the spectral region between 1650 and $925 \mathrm{~cm}^{-1}$ and were able to find significant differences between cells, mainly an increase of intensity of bands at 1240, 1120 and $1080 \mathrm{~cm}^{-1}(69)$. Regarding the band at $1240 \mathrm{~cm}^{-}$ 1 , a shift to a higher frequency was observed in cancer cells (peak maximum absorbance at $\sim 1241.5 \mathrm{~cm}^{-1}$ ), compared to the peak maximum absorbance at $\sim 1236.9 \mathrm{~cm}^{-1}$ presented by the normal epithelial cells, suggesting an alteration in the hydrogen bonds in the phosphodiester groups of the DNA in cancer cells. As for the band at $1080 \mathrm{~cm}^{-1}$, authors observed a shift to a higher frequency in two cancer cells (AGS and SNU-1) in comparison to the one detected in normal cells $\left(1085.7 \mathrm{~cm}^{-1}\right.$ and $1081.9 \mathrm{~cm}^{-1}$, respectively). This shift can be attributed to the tighter packing of DNA molecules in the cancer cells. On the other hand, a shift to a lower frequency was registered in the $\mathrm{NCl}$ N87 cell line (1081.5 cm-1) (69). Finally, the increased IR absorbance observed in the cell lines in the band at $1120 \mathrm{~cm}^{-1}$ was due to an increment of RNA content in these cells. Given these results, the authors concluded that the changes observed in the spectra were all associated with an increase in the phosphate backbone, corresponding to an increase in DNA and RNA content in the cancer cell lines (69). 
A few studies using FTIR spectroscopy have also been carried out in breast cancer cell lines. In 2008, Hwang and colleagues studied the $4000-2400 \mathrm{~cm}^{-1}$ region to evaluate lipids in cell lines MCF 10A (normal cell line), MCF7 (cancer cell line) and MDA-MB-231 (invasive cancer cell line) (70). They observed major absorption bands at 3683, 3664 $3641,3621,2923,2873$ and $2854 \mathrm{~cm}^{-1}$, with notable differences at 3621 and $2873 \mathrm{~cm}^{-1}$ that were only observed in the MCF $10 \mathrm{~A}$ cell line. Their results suggest that cancer cells exhibit a stronger bonding structure in the membrane lipids compared to normal cells (70). In 2010, Mostaço-Guidolin and colleagues focused on the study of the MCF7 and SKBr3 cells, which are estrogen receptor positive and negative, respectively (71). Their results indicate that the MCF7 cell line shows increased absorbance intensity in the bands at 1085 (DNA), 1542 (amide II) and $1650 \mathrm{~cm}^{-1}$ (amide I), compared to the SKBr3 cell line. Furthermore, differences in the $3000-2800 \mathrm{~cm}^{-1}$ region were detected. Their results suggest that SKBr3 cells show an increased IR absorbance in the lipids region, mainly in the bands at 2962 and $2924 \mathrm{~cm}^{-1}(71)$.

In the field of lung cancer, Lee and colleagues conducted a study in which they compared two cancer cell lines ( $\mathrm{NCl}-\mathrm{H} 358$ and $\mathrm{NCl}-\mathrm{H} 460)$ to normal human bronchial epithelial (NHBE) cells (72). They observed that the bands at 1085 and $970 \mathrm{~cm}^{-1}$ were increased in the cancer cells. These bands are assigned to the symmetric stretching of $\mathrm{PO}_{3}{ }^{2-}$ and $\mathrm{PO}_{2}{ }^{-}$, respectively, and the authors attributed this result to an increase of phosphorylation that occurs in cancer cells. Apart from this result, they verified that bands at $\sim 1030$ and $\sim 1155 \mathrm{~cm}^{-1}$ were more intense in normal cells, suggesting a decrease of glycogen in cancer cells, as was previously reported by Wong and colleagues $(72,73)$.

Hematological diseases cancers have also been subject to IR spectroscopic studies. Babrah et al. studied five cell lines derived from human leukemias and lymphomas: Karpas 299 (T-cell lymphoma cell line), REH (acute lymphoid cell line), RCHACV (acute lymphoid cell line), HL60 (acute myeloid leukemia cell line) and Meg01 (chronic myeloid cell line) (74). The results indicated notable changes in the 1500-900 $\mathrm{cm}^{-1}$ region, mainly an increase of the intensity of the amide III and DNA bands. This increase might indicate an increment of cellular nuclear content, shedding light on the biochemical differences that exist between the cell lines (74). 
In what concerns investigation of drug-resistant cell lines, the band at $1740 \mathrm{~cm}^{-1}$ was subject to a couple of studies. Gaigneaux and colleagues were able to determine significant differences in the lipid content between sensitive K562 cells derived from human chronic myelogenous leukemia (K562/DNS) and its multiresistant variant (K562/DNR). A reduction of the intensity of the band in K562/DNR cells suggested a decrease of lipid content (75). Zwielly and colleagues focused on the discrimination of two melanoma cell lines based on their sensitivity to cisplatin: GA (sensitive parental cell line) and GAC (cisplatin-resistant cell line derived from GA). Unlike K562/DNR cells (75), these results indicated an increase of the intensity of the band at $1740 \mathrm{~cm}^{-1}$ in the GAC cell line (38). These opposite results can be attributed to the number of passages the cells were subjected to. Le Moyec et al. verified that after several passages in the absence of the anticancer drug, K562 cells partially recovered their lipid content (76).

A recent investigation, carried out by Minnes et al., determined that FTIR spectroscopy could also be useful in distinguishing cancer cells with distinct metastatic potentials (77). It has already been proven that metastatic cells exhibit a higher level of fluidity of the cell membrane, which can be associated with a higher level of hydration $(78,79)$. Additionally, an increase in the level of hydration is followed by an increment in the absorption intensity of proteins (80). In this study, two pairs of melanoma cell lines were utilized: murine B16-F1 and B16-F10, and human WM-115 and WM-266.4. It was concluded that cells with a higher metastatic potential (B16-F10 and WM-266.4) exhibited a higher absorption intensity of the band at $1540 \mathrm{~cm}^{-1}$ (amide II), in comparison to the cells with a low-metastatic potential (B16-F1 and WM-115), which can be attributed to the higher level of hydration of the cell membrane (77). To sum up all these results, table 2 presents the main spectral characteristics of cancer cell lines.

\section{b. Potential spectral biomarkers}

Apart from the spectral differences between different cancer cells, ratios between specific mid-IR bands have been regarded as potential biomarkers. Gazi et al. explored the peak area ratio of $1030 \mathrm{~cm}^{-1} / 1080 \mathrm{~cm}^{-1}$, which corresponds to the glycogen/phosphate ratio, as a potential diagnostic biomarker (36). This ratio correlates with the metabolic turnover of cells, and lower values are observed in malignant cell lines. However, non-malignant cell line PNT2-C2 also exhibits a low ratio, which the 
authors attributed to the transformation process that cells had to undergo in order to become immortal (36).

In a study comparing two K562 cell lines (75), a decrease of the lipid/protein and nucleic acid/protein ratios, in the $3000-2800 \mathrm{~cm}^{-1}$ and $1300-900 \mathrm{~cm}^{-1}$ regions, respectively, was detected in the K562/DNR cells. However, a higher $2871 \mathrm{~cm}^{-1} / 2853$ $\mathrm{cm}^{-1}$ ratio was observed in K562/DNR cells, which can be attributed either to the decrease of lipid content in resistant cells or to the modification of the membrane composition (75). Characteristic IR absorptions were also found at the bands at $2958 \mathrm{~cm}^{-}$ ${ }^{1}$ (methyl groups of lipids and proteins) and $2852 \mathrm{~cm}^{-1}$ (methylene chains in membrane lipids) in GA and GAC cells, and the ratio between these two frequencies was considered a potential biomarker to distinguish the two types of cells, with a lower ratio observed in resistant cells (38). Furthermore, lipid/protein ratios using the intensities at 1740 and $1400 \mathrm{~cm}^{-1}$ were assessed, and a noteworthy increase of the ratio in resistant cells was detected. The increase of the intensity of the bands at 2852 and $1740 \mathrm{~cm}^{-1}$ can be used to monitor lipids in resistant cells and, therefore, is considered a diagnostic parameter that can be associated with drug resistance (38). Also, another potential biomarker was found in the $1200-1000 \mathrm{~cm}^{-1}$ region, which was associated to the ratio between RNA $\left(1121 \mathrm{~cm}^{-1}\right)$ and DNA $\left(1022 \mathrm{~cm}^{-1}\right)$. It was found that, in resistant cells, this ratio was higher compared to normal cells (38).

\section{c. Multivariate analysis applied to FTIR spectra of cancer cell lines}

Besides direct spectra analysis, multivariate statistical analysis is a powerful tool to analyze FTIR spectra and has gained an important role in the discrimination of several cell lines $(36,41)$. Wood et al. carried out a study in which they compared HeLa cells (derived from cervical cancer) to normal and malignant exfoliated cells (81). Using PCA a clear separation was observed between normal and malignant exfoliated cells. Furthermore, HeLa cells were grouped with the malignant cells, validating the spectral similarities between HeLa and malignant exfoliated cells (81).

In 2003, Gazi and colleagues were able to discriminate, for the first time, prostate cancer cell lines derived from distinct metastatic sites based on their IR spectra (36). Using PCA, they discriminated three cell lines used as models for prostate cancer: DU 145 (derived from brain metastasis), PC-3 (derived from bone metastasis) and non- 
malignant PNT2-C2 (normal prostate epithelial cells transformed with the genome of SV40 virus to express the large T antigen) (36). In 2009, Harvey and colleagues carried out a similar study, in which they also compared prostate cancer cell lines: PC-3, PNT2C2 and LNCaP, which is derived from lymph node metastasis. Using the spectral region between 1481-800 $\mathrm{cm}^{-1}$, they were able to discriminate the cells based on their spectra and discard possible factors that could have influenced the discrimination of the prostate cell lines reported by Gazi et al. (41). To do so, they studied the effect of the growth media and the nucleus/cytoplasm ratio on this discrimination and verified that neither were able to explain it. Therefore, they concluded that the intrinsic biochemical differences between the cell lines were the main factor for discrimination, proving also the robustness of PCA analysis (41).

Regarding human melanoma cells studied by Zwielly et al., a distinct discrimination between the GA and GAC cells was observed after PCA analysis (38). Also, human leukemia and lymphoma cell lines investigated by Babrah et al. were clearly discriminated by PCA, unveiling the potential of both FTIR spectroscopy and multivariate analysis for the early detection of leukemia and lymphoma (74).

Despite these promising results, the use of cell lines as cancer models was put in doubt in a study carried out by Baker and colleagues on the prostate-derived RWPE family of cell lines (RWPE-1, RWPE-2, WPE1-NA22, WPE1-NB14, WPE1-NB11 and WPE1NB26) (47). Non-tumorigenic cell line RWPE-1 is derived from a normal adult prostate epithelial cell transformed with a single copy of the human papillomavirus-18 and the tumorigenic cell line RWPE-2 is the result of the transformation of RWPE-1 cells with Kiras. Also, WPE1-NA22, WPE1-NB14, WPE1-NB11 and WPE1-NB26 cell lines were created upon the exposure of RWPE-1 to N-methyl-N-nitrosourea and exhibit increasing invasiveness (47). Using principal component - discriminant function analysis (PC-DFA), authors observed a clear discrimination of the cells. However, these results indicated that biochemical changes associated with invasiveness were not responsible for the discrimination, but rather the biochemical changes induced by different transformation methods (genetic vs. genetic and chemical) (47). Despite this, it is important to point out that FTIR spectroscopy is a suitable technique to study cancer cell lines and it is important to continue the development of new spectroscopic based applications for 
studying malignant cells, keeping in mind that the appropriate controls must always be used in order to be confident of the results (82). Apart from the control sample selection, it is important to define and validate all the experimental design, in particular the biological replicates and the standardization of spectral acquisition conditions. During the spectroscopic data analysis, after a meticulous and exploratory direct spectra analysis, the choice of pre-treatments and the selection of the appropriate spectral region to study are of utmost importance and crucial to the success of the experiment.

\section{Concluding remarks}

Cancer cells have distinct features that separate them from normal cells. Several alterations regarding the content of lipids, proteins, nucleic acids and carbohydrates have been identified in cancer cells by FTIR spectroscopy.

Membrane lipids seem to have a stronger bonding structure in cancer cells in comparison to normal cells. Furthermore, analysis of the band at $1740 \mathrm{~cm}^{-1}$ can give insights on an increased intensity in the band at $1740 \mathrm{~cm}^{-1}$ ean be used to monitor lipids in drug resistant cells and it is possibly associated with drug resistance. As for differences detected in the main protein bands (amide I and amide II), the most striking alteration is the increase of the relative amount of $\beta$-sheets in some cancer cells, which might indicate protein aggregation. Carbohydrates, particularly glycogen, are found to be decreased in cancer cells in comparison to normal cells. Furthermore, differences regarding DNA and RNA are have been detected and are mainly associated with an increase of their content and a tighter packing of DNA in cancer cells.

This review highlighted the potential of FTIR spectroscopy to detect biochemical differences between distinct groups of cells. Given the fact that biochemical changes precede morphological alterations, it is likely that this technique could allow for an early diagnosis of cancer. Nevertheless, other metabolomics techniques, such as NMR and mass spectrometry, should be considered to complement results obtained by FTIR spectroscopy and discover specific metabolites that could be involved in cancer initiation and progression. 


\section{References}

1. Siegel RL, Miller KD, Jemal A. Cancer statistics, 2018. CA Cancer J Clin. 2018;68(1):7-30.

2. Cancer [Internet]. WHO. 2018 [cited 2018 Feb 15]. Available from: http://www.who.int/mediacentre/factsheets/fs297/en/

3. Kendall C, Isabelle M, Bazant-Hegemark F, Hutchings J, Orr L, Babrah J, et al. Vibrational spectroscopy: a clinical tool for cancer diagnostics. Analyst. 2009;134(6):1029.

4. Machado Lopes J, Rocha-Gonçalves F, Borges M, Redondo P, Laranja-Pontes J. The cost of cancer treatment in Portugal. Ecancermedicalscience. 2017 Sep 6;11:110.

5. Old OJ, Fullwood LM, Scott R, Lloyd GR, Almond LM, Shepherd NA, et al. Vibrational spectroscopy for cancer diagnostics. Anal Methods. 2014;6(12):3901.

6. Lee D, Fontugne J, Gumpeni N, Park K, Macdonald TY, Robinson BD, et al. Molecular alterations in prostate cancer and association with MRI features. Prostate Cancer Prostatic Dis. 2017;20(4):430-5.

7. Denkert C, Liedtke C, Tutt A, von Minckwitz G. Molecular alterations in triplenegative breast cancer-the road to new treatment strategies. Lancet. 2017;389(10087):2430-42.

8. Cordon-Cardo C. Molecular alterations associated with bladder cancer initiation and progression. Scand J Urol Nephrol. 2008 Jan 31;42(sup218):154-65.

9. Hanahan D, Weinberg RA. Hallmarks of cancer: The next generation. Cell. 2011;144(5):646-74.

10. Pavlova NN, Thompson CB. The Emerging Hallmarks of Cancer Metabolism. Cell Metab. 2016;23(1):27-47.

11. DeBerardinis RJ, Chandel NS. Fundamentals of cancer metabolism. Sci Adv. 2016;2(5).

12. Ma Y, Zhang $P$, Yang $Y$, Wang F, Qin H. Metabolomics in the fields of oncology: a review of recent research. Mol Biol Rep. 2012 Jul 16;39(7):7505-11.

13. Serkova NJ, Glunde K. Metabolomics of Cancer. Vol. 520, Tumor Biomarker Discovery. 2009.

14. Mondul AM, Moore SC, Weinstein SJ, Männistö S, Sampson JN, Albanes D. 1Stearoylglycerol is associated with risk of prostate cancer: results from a serum metabolomic profiling analysis. Metabolomics. 2014 Oct 7;10(5):1036-41.

15. Giskeødegård GF, Bertilsson $\mathrm{H}$, Selnæs KM, Wright AJ, Bathen TF, Viset $T$, et al. Spermine and Citrate as Metabolic Biomarkers for Assessing Prostate Cancer Aggressiveness. Monleon D, editor. PLoS One. 2013 Apr 23;8(4):e62375.

16. Jain M, Nilsson R, Sharma S, Madhusudhan N, Kitami T, Souza AL, et al. Metabolite 
Profiling Identifies a Key Role for Glycine in Rapid Cancer Cell Proliferation. Science (80- ). 2012 May 25;336(6084):1040-4.

17. Ellis DI, Dunn WB, Griffin JL, Allwood JW, Goodacre R. Metabolic fingerprinting as a diagnostic tool. Pharmacogenomics. 2007;8(9):1243-66.

18. Zhang A, Yan G, Han Y, Wang X. Metabolomics Approaches and Applications in Prostate Cancer Research. Appl Biochem Biotechnol. 2014 Sep 18;174(1):6-12.

19. Mackay E, Bathe OF. Cancer metabolomics and its practical applications. Glob Metab Profilling Clin Appl. 2014;70-83.

20. Kwon H, Oh S, Jin X, An YJ, Park S. Cancer metabolomics in basic science perspective. Arch Pharm Res. 2015 Mar 30;38(3):372-80.

21. Vermeersch KA, Styczynksi MP. Applications of Metabolomics in Cancer Studies. In: Journal of Carcinogenesis. 2013. p. 1-9.

22. Kaddurah-Daouk R, Kristal BS, Weinshilboum RM. Metabolomics: A Global Biochemical Approach to Drug Response and Disease. Annu Rev Pharmacol Toxicol. 2008;48(1):653-83.

23. Nassar A-EF, Talaat RE. Strategies for dealing with metabolite elucidation in drug discovery and development. Drug Discov Today. 2004 Apr;9(7):317-27.

24. Naumann D. FT-INFRARED AND FT-RAMAN SPECTROSCOPY IN BIOMEDICAL RESEARCH. Appl Spectrosc Rev. 2001 Jun 30;36(2-3):239-98.

25. Olsztynska-Janus S, Szymborska-Malek K, Gasior-Glogowska M, Walski T, Komorowska M, Witkeiwicz W, et al. Spectroscopic techniques in the study of human tissues and their components. Part I: IR spectroscopy. Acta Bioeng Biomech. 2012;14(3):101-15.

26. Singh B, Gautam R, Kumar S, Vinay Kumar BN, Nongthomba U, Nandi D, et al. Application of vibrational microspectroscopy to biology and medicine. Curr Sci. 2012;102(2):232-44.

27. Othman NH, El-tawil SG. FTIR Spectroscopy: A New Technique In Cancer Diagnoses. US Chinese J Lymphology Oncol. 2009;8(1):10-4.

28. Stuart BH. Infrared Spectroscopy Of Biological Applications: An Overview. Encycl Anal Chem. 2012;529-58.

29. Stuart BH. Infrared Spectroscopy: Fundamentals and Applications. Vol. 8, Methods. 2004. 224 p.

30. Sahu R, Mordechai S. Fourier transform infrared spectroscopy in cancer detection. Futur Oncol. 2005;1(5):635-47.

31. Sahu RK, Mordechai S. The Increasing Relevance of FTIR Spectroscopy in Biomedicine. J Med Phys Appl Sci. 2015;1(1):1-3.

32. Yano K, Sakamoto Y, Hirosawa N, Tonooka S, Katayama H, Kumaido K, et al. Applications of Fourier transform infrared spectroscopy, Fourier transform infrared microscopy and near-infrared spectroscopy to cancer research. 
Spectrosc Int J. 2003;17(2-3):315-21.

33. Talari ACS, Martinez MAG, Movasaghi Z, Rehman S, Rehman IU. Advances in Fourier transform infrared (FTIR) spectroscopy of biological tissues. Appl Spectrosc Rev. 2017;52(5):456-506.

34. Schmitt J, Flemming H-C. FTIR-spectroscopy in microbial and material analysis. Int Biodeterior Biodegradation. 1994;41:1-11.

35. Correia M, Lopes J, Silva R, Rosa IM, Henriques AG, Delgadillo I, et al. FTIR Spectroscopy -A Potential Tool to Identify Metabolic Changes in Dementia. HSOA J Alzheimer's Neurodegener Dis. 2016;(Building 30).

36. Gazi E, Dwyer J, Gardner P, Ghanbari-Siahkali A, Wade AP, Miyan J, et al. Applications of Fourier transform infrared microspectroscopy in studies of benign prostate and prostate cancer. A pilot study. J Pathol. 2003;201(1):99-108.

37. Liu K-Z, Xu M, Scott DA. Biomolecular characterisation of leucocytes by infrared spectroscopy. Br J Haematol. 2007;136(5):713-22.

38. Zwielly A, Gopas J, Brkic G, Mordechai S. Discrimination between drug-resistant and non-resistant human melanoma cell lines by FTIR spectroscopy. Analyst. 2009;134(2):294-300.

39. Gazi E, Baker M, Dwyer J, Lockyer NP, Gardner P, Shanks JH, et al. A Correlation of FTIR Spectra Derived from Prostate Cancer Biopsies with Gleason Grade and Tumour Stage. Eur Urol. 2006;50(4):750-61.

40. Harvey TJ, Henderson A, Gazi E, Clarke NW, Brown M, Faria EC, et al. Discrimination of prostate cancer cells by reflection mode FTIR photoacoustic spectroscopy. Analyst. 2007;132(4):292.

41. Harvey TJ, Gazi E, Henderson A, Snook RD, Clarke NW, Brown M, et al. Factors influencing the discrimination and classification of prostate cancer cell lines by FTIR microspectroscopy. Analyst. 2009;134(6):1083-91.

42. Dukor RK. Vibrational Spectroscopy in the Detection of Cancer. Handb Vib Spectrosc. 2006;3335-60.

43. Wang L, Mizaikoff B. Application of multivariate data-analysis techniques to biomedical diagnostics based on mid-infrared spectroscopy. Anal Bioanal Chem. 2008;391(5):1641-54.

44. Magalhães S, Graça A, Tavares J, Santos MAS, Delgadillo I, Nunes A. Saccharomyces cerevisiae as a Model to Confirm the Ability of FTIR to Evaluate the Presence of Protein Aggregates. Spectr Anal Rev. 2018;6(1):1-11.

45. Worley B, Powers R. Multivariate Analysis in Metabolomics. Curr Metabolomics. 2013;1(1):92-107.

46. Sussulini A. Metabolomics : From Fundamentals to Clinical Applications. 2017. 1$351 \mathrm{p}$.

47. Baker MJ, Clarke C, Démoulin D, Nicholson JM, Lyng FM, Byrne HJ, et al. An 
investigation of the RWPE prostate derived family of cell lines using FTIR spectroscopy. Analyst. 2010;135(5):887-94.

48. Diem M, Boydston-White S, Chiriboga L. Infrared spectroscopy of cells and tissues: shining light onto a novel subject. Appl Spectrosc. 1999;53(4):148-61.

49. Kaur G, Dufour JM. Cell lines: Valuable tools or useless artifacts. Spermatogenesis. 2012;2(1):1-5.

50. Masters JRW. Human cancer cell lines: fact and fantasy. Nat Rev Mol Cell Biol. 2000;1(3):233-6.

51. Ulrich AB, Pour PM. Cell Lines. Encycl Genet. 2001;310-1.

52. van Staveren WCG, Solís DYW, Hébrant A, Detours V, Dumont JE, Maenhaut C. Human cancer cell lines: Experimental models for cancer cells in situ? For cancer stem cells? Biochim Biophys Acta. 2009;1795(2):92-103.

53. Gillet J-P, Varma S, Gottesman MM. The Clinical Relevance of Cancer Cell Lines. J Natl Cancer Inst. 2013;105(7):452-8.

54. Ferreira D, Adega F, Chaves R. The Importance of Cancer Cell Lines as in vitro Models in Cancer Methylome Analysis and Anticancer Drugs Testing. Oncogenomics and Cancer Proteomics - Novel Approaches in Biomarkers Discovery and Therapeutic Targets in Cancer. 2013. 139-166 p.

55. Louzada S, Adega F, Chaves R. Defining the sister rat mammary tumor cell lines $\mathrm{HH}-16 \mathrm{cl} .2 / 1$ and HH-16.cl.4 as an In Vitro cell model for Erbb2. PLoS One. 2012;7(1).

56. Clemens G, Hands JR, Dorling KM, Baker MJ. Vibrational spectroscopic methods for cytology and cellular research. Analyst. 2014;139(18):4411-44.

57. Rigas B, Wong PTT. Human Colon Adenocarcinoma Cell Lines Display Infrared Spectroscopic Features of Malignant Colon Tissues. Cancer Res. 1992;52(1):84-8.

58. Walsh MJ, Singh MN, Stringfellow HF, Pollock HM, Hammiche A, Grude O, et al. FTIR microspectroscopy coupled with two-class discrimination segregates markers responsible for inter- and intra-category variance in exfoliative cervical cytology. Biomark Insights. 2008;2008(3):179-89.

59. Rigas B, Morgello S, Goldman IS, Wong PT. Human colorectal cancers display abnormal Fourier-transform infrared spectra. Proc Natl Acad Sci U S A. 1990;87(20):8140-4.

60. Wong PTT, Papavassiliou ED, Rigas B. Phosphodiester Stretching Bands in the Infrared Spectra of Human Tissues and Cultured Cells. Appl Spectrosc. 1991;45(9):1563-7.

61. Barth A, Zscherp C. What vibrations tell about proteins. Q Rev Biophys. 2002;35(4):369-430.

62. Shivu B, Seshadri S, Li J, Oberg KA, Uversky VN, Fink AL. Distinct $\beta$-sheet structure in protein aggregates determined by ATR-FTIR spectroscopy. Biochemistry. 
2013;52(31):5176-83.

63. Koo EH, Lansbury PT, Kelly JW. Amyloid diseases: Abnormal protein aggregation in neurodegeneration. Proc Natl Acad Sci. 1999;96(18):9989-90.

64. Levy CB, Stumbo AC, Ano Bom APD, Portari EA, Carneiro Y, Silva JL, et al. Colocalization of mutant $\mathrm{p} 53$ and amyloid-like protein aggregates in breast tumors. Int J Biochem Cell Biol. 2011;43(1):60-4.

65. Xu J, Reumers J, Couceiro JR, De Smet F, Gallardo R, Rudyak S, et al. Gain of function of mutant $\mathrm{p} 53$ by coaggregation with multiple tumor suppressors. Nat Chem Biol. 2011;7(5):285-95.

66. Yang-Hartwich Y, Bingham J, Garofalo F, Alvero AB, Mor G. Detection of p53 Protein Aggregation in Cancer Cell Lines and Tumor Samples. In: Apoptosis and Cancer: Methods and Protocols. 2015. p. 75-86.

67. Neviliappan S, Fang Kan L, Tiang Lee Walter T, Arulkumaran S, Wong PTT. Infrared spectral features of exfoliated cervical cells, cervical adenocarcinoma tissue, and an adenocarcinoma cell line (SiSo). Gynecol Oncol. 2002;85(1):170-4.

68. Bishop JM. Viral oncogenes. Vol. 42, Cell. 1985. p. 23-38.

69. Fujioka N, Morimoto Y, Arai T, Takeuchi K, Yoshioka M, Kikuchi M. Differences between infrared spectra of normal and neoplastic human gastric cells. Spectroscopy. 2004;18(1):59-66.

70. Hwang EJ, Lee SK, Kwak YH, Park SS, Hong SM. Live cells detection in breast cellline by FTIR micro-spectrometer. In: Proceedings of IEEE Sensors. 2008. p. 87881.

71. Mostaço-Guidolin LB, Murakami LS, Batistuti MR, Nomizo A, Bachmann L. Molecular and chemical characterization by Fourier transform infrared spectroscopy of human breast cancer cells with estrogen receptor expressed and not expressed. Spectroscopy. 2010;24(5):501-10.

72. Lee SY, Yoon KA, Jang SH, Ganbold EO, Uuriintuya D, Shin SM, et al. Infrared spectroscopy characterization of normal and lung cancer cells originated from epithelium. J Vet Sci. 2009;10(4):299-304.

73. Wong PT, Wong RK, Caputo T a, Godwin T a, Rigas B. Infrared spectroscopy of exfoliated human cervical cells: evidence of extensive structural changes during carcinogenesis. Biochemistry. 1991;88(24):10988-92.

74. Babrah J, McCarthy K, Lush RJ, Rye AD, Bessant C, Stone N. Fourier transform infrared spectroscopic studies of T-cell lymphoma, B-cell lymphoid and myeloid leukaemia cell lines. Analyst. 2009;134(4):763-8.

75. Gaigneaux A, Ruysschaert JM, Goormaghtigh E. Infrared spectroscopy as a tool for discrimination between sensitive and multiresistant K562 cells. Eur J Biochem. 2002;269(7):1968-73.

76. Le Moyec L, Tatoud R, Degeorges A, Calabresse C, Bauza G, Eugène M, et al. Proton nuclear magnetic resonance spectroscopy reveals cellular lipids involved 
in resistance to adriamycin and taxol by the K562 leukemia cell line. Cancer Res. 1996;56(15):3461-7.

77. Minnes R, Nissinmann M, Maizels $Y$, Gerlitz G, Katzir A, Raichlin Y. Using Attenuated Total Reflection-Fourier Transform Infra-Red (ATR-FTIR) spectroscopy to distinguish between melanoma cells with a different metastatic potential. Sci Rep. 2017;7(1):4381.

78. Taraboletti G, Perin L, Bottazzi B, Mantovani A, Giavazzi R, Salmona M. Membrane fluidity affects tumor-cell motility, invasion and lung-colonizing potential. Int J Cancer. 1989;44(4):707-13.

79. Parasassi T, Di Stefano M, Loiero M, Ravagnan G, Gratton E. Cholesterol modifies water concentration and dynamics in phospholipid bilayers: a fluorescence study using Laurdan probe. Biophys J. 1994;66(3):763-8.

80. Pevsner A, Diem M. Infrared Spectroscopic Studies of Major Cellular Components. Part I: The Effect of Hydration on the Spectra of Proteins. Appl Spectrosc. 2001;55(6):788-93.

81. Wood BR, Quinn MA, Burden FR, McNaughton D. An Investigation Into FTIR Spectroscopy As A Biodiagnostic Tool For Cervical Cancer. Biospectroscopy. 1996;2:143-53.

82. Erukhimovitch V, Talyshinsky $M$, Souprun $Y$, Huleihel $M$. Spectroscopic characterization of human and mouse primary cells, cell lines and malignant cells. Photochem Photobiol. 2002;76(4):446-51.

83. Bellisola G, Sorio C. Infrared spectroscopy and microscopy in cancer research and diagnosis. Am J Cancer Res. 2012;2(1):1-21.

84. Parker F. Applications of Infrared Spectroscopy in Biochemistry, Biology, and Medicine. 1971. 602 p. 


\section{Tables}

Table 1: Major vibrational modes and corresponding assignments found in biological samples.

\begin{tabular}{|c|c|c|c|}
\hline Wavenumber $\left(\mathrm{cm}^{-1}\right)$ & Vibrational mode & Assigned biochemical component & Reference \\
\hline$\sim 3300$ & $\mathrm{~N}-\mathrm{H}$ stretching & Amide A: peptide, protein & $(28,83)$ \\
\hline$\sim 3100$ & $\mathrm{~N}-\mathrm{H}$ stretching & Amide B: peptide, protein & $(28,83)$ \\
\hline$\sim 2960$ & $\mathrm{CH}_{3}$ asymmetric stretching & \multirow{4}{*}{ Lipids } & \multirow{4}{*}{$(24,70,71)$} \\
\hline$\sim 2925$ & $\mathrm{CH}_{2}$ asymmetric stretching & & \\
\hline$\sim 2870$ & $\mathrm{CH}_{3}$ symmetric stretching & & \\
\hline$\sim 2853$ & $\mathrm{CH}_{2}$ symmetric stretching & & \\
\hline$\sim 1740$ & $\mathrm{C}=\mathrm{O}$ stretching & Phospholipid esters & $(24,48,83)$ \\
\hline$\sim 1683$ & \multirow{3}{*}{$\begin{array}{c}\mathrm{C}=\mathrm{O} \text { stretching, } \mathrm{C}-\mathrm{N} \text { stretching, in-plane } \\
\mathrm{N}-\mathrm{H} \text { bending }\end{array}$} & Amide I: antiparallel $\beta$-sheets & $(24,57)$ \\
\hline$\sim 1650$ & & Amide I: $\alpha$-helices & $(24,57)$ \\
\hline$\sim 1635$ & & Amide I: parallel $\beta$-sheets & $(24,57)$ \\
\hline$\sim 1550-1520$ & $\begin{array}{l}\mathrm{N}-\mathrm{H} \text { stretching, C-N stretching, } \mathrm{C}-\mathrm{C} \\
\text { stretching }\end{array}$ & Amide II & $(24,83)$ \\
\hline$\sim 1460-1400$ & $\mathrm{CH}_{3}$ and $\mathrm{CH}_{2}$ deformation & Membrane lipids and proteins & $(67,74,83)$ \\
\hline$\sim 1380$ & $\mathrm{CH}_{3}$ symmetric wagging & Phospholipid, fatty acid, triglyceride & (83) \\
\hline$\sim 1310-1200$ & $\begin{array}{l}\mathrm{N}-\mathrm{H} \text { bending, } \mathrm{C}-\mathrm{N} \text { stretching, } \mathrm{C}=\mathrm{O} \\
\text { stretching, } \mathrm{C}-\mathrm{C} \text { stretching, } \mathrm{CH}_{3} \text { stretching }\end{array}$ & Amide III & $(24,83,84)$ \\
\hline$\sim 1240$ & $\mathrm{PO}_{2}^{-}$symmetric stretching & Nucleic acids & $(27,69)$ \\
\hline 1170 & C-O stretching & $\begin{array}{l}\text { Tyrosine, serine and threonine of cell } \\
\text { proteins }\end{array}$ & (67) \\
\hline 1155 & $\mathrm{C}-\mathrm{O}$ stretching, $\mathrm{C}-\mathrm{O}-\mathrm{H}$ bending & Carbohydrates & (67) \\
\hline $1122-1120$ & $\begin{array}{l}\text { Vibration mode of the } \mathrm{PO}_{2} \text { of the } \\
\text { phosphodiester groups }\end{array}$ & RNA & $(69,71)$ \\
\hline $1086-1080$ & $\mathrm{PO}_{2}^{-}$symmetric stretching & $\begin{array}{c}\text { DNA, RNA, phospholipid, phosphorylated } \\
\text { protein }\end{array}$ & $(67,69)$ \\
\hline 1047,1025 & $\mathrm{C}-\mathrm{O}$ stretching and bending of $\mathrm{C}-\mathrm{OH}$ & Glycogen & (67) \\
\hline $972-970$ & $\mathrm{PO}_{3}{ }^{2-}$ symmetric stretching & $\begin{array}{l}\text { Dianionic phosphate monoesters of } \\
\text { phosphorylated proteins and nucleic acids }\end{array}$ & $(67,70)$ \\
\hline
\end{tabular}


Table 2: Specific spectral characteristics for cancer cell lines.

\begin{tabular}{|c|c|c|}
\hline Mid-IR region & IR frequency & Alterations in the IR spectra \\
\hline \multirow{4}{*}{$3000-2800 \mathrm{~cm}^{-1}$} & $2962 \mathrm{~cm}^{-1}$ & \multirow{2}{*}{ Increased intensity in SKBr3 } \\
\hline & $2924 \mathrm{~cm}^{-1}$ & \\
\hline & $2873 \mathrm{~cm}^{-1}$ & Increased intensity in MCF 10A \\
\hline & $2852 \mathrm{~cm}^{-1}$ & Increased intensity in GAC \\
\hline \multirow{6}{*}{$1800-1300 \mathrm{~cm}^{-1}$} & \multirow{2}{*}{$1740 \mathrm{~cm}^{-1}$} & \\
\hline & & Decreased intensity in K562/DNR \\
\hline & $1700-1600 \mathrm{~cm}^{-1}$ & $\begin{array}{l}\text { Increased number of } \beta \text {-sheets in LoVo, SW1116, HCT-15, } \\
\text { SW403, SW480 and SKC01 }\end{array}$ \\
\hline & $1650 \mathrm{~cm}^{-1}$ & Increased intensity in MCF7 \\
\hline & $1542-1540 \mathrm{~cm}^{-1}$ & Increased intensity in B16-F1, WM-115 and MCF7 \\
\hline & $1400 \mathrm{~cm}^{-1}$ & Shift in the spectrum of SiSo \\
\hline \multirow{10}{*}{$1300-900 \mathrm{~cm}^{-1}$} & $1242 \mathrm{~cm}^{-1}$ & $\begin{array}{l}\text { Increased intensity in Karpas 299, REH, RCH-ACV, HL60 and } \\
\text { Meg01 }\end{array}$ \\
\hline & $1240 \mathrm{~cm}^{-1}$ & Shift in the frequency in AGS, SNU-1 and NCl-N87 \\
\hline & $1170 \mathrm{~cm}^{-1}$ & Increased intensity in SiSo \\
\hline & $1155 \mathrm{~cm}^{-1}$ & Decreased intensity in SiSo \\
\hline & $1120 \mathrm{~cm}^{-1}$ & Increased intensity in AGS, SNU-1 and NCl-N87 \\
\hline & $\sim 1086-1080 \mathrm{~cm}^{-1}$ & $\begin{array}{l}\text { Shift in the frequency in LoVo, SW1116, HCT-15, SW403, } \\
\text { SW480, SKC01, SiSo, AGS, SNU-1 and NCI-N87 }\end{array}$ \\
\hline & & Increased intensity in $\mathrm{NCl}-\mathrm{H} 358, \mathrm{NCl}-\mathrm{H} 460$ and MCF7 \\
\hline & $1047 \mathrm{~cm}^{-1}$ and $1030-1025 \mathrm{~cm}^{-1}$ & Decreased intensity in SiSo, $\mathrm{NCl}-\mathrm{H} 358$ and $\mathrm{NCl}-\mathrm{H} 460$ \\
\hline & $991 \mathrm{~cm}^{-1}$ & $\begin{array}{l}\text { Present in LoVo, SW1116, HCT-15, SW403, SW480 and } \\
\text { SKC01 }\end{array}$ \\
\hline & $972-970 \mathrm{~cm}^{-1}$ & $\begin{array}{l}\text { Increased intensity in LoVo, SW1116, HCT-15, SW403, } \\
\text { SW480, SKC01, SiSo, NCl-H358 and NCI-H460 }\end{array}$ \\
\hline
\end{tabular}

